Technical Paper

\title{
Inter-Comparison of the Long-Run Coefficients between the Both Prices of LNG and Crude Oil of Japan, EU and USA
}

\author{
Qi ZHANG, Hidekazu YosHIKAWA, Hirotake IsHII, and Hiroshi SHIMODA
}

(Received August 8, 2007)

\begin{abstract}
The quantitative co-relationships between the time series of Liquid Natural Gas (LNG) CIF (Cost, Insurance and Freight) prices and those of crude oil prices were estimated for Japan, EU and USA based on the monthly price data in the time period from early of 1998 to 2006 of the three regional markets. Since both prices of LNG CIF and crude oil appear to be non-stationary, the cointegration and the Error Correction Model (ECM) techniques were applied to obtain the long-run elasticity coefficients between both prices of LNG CIF and crude oil for these three markets. The obtained results suggest that 100 percent changes of the crude oil prices of Japan, EU and USA have 49 percent, 76 percent and 96 percent impacts on the respective LNG CIF prices in a long term when the crude oil price in a relative high era. The obtained long-run elasticity coefficients can be used to explain the different price changes of LNG CIF in each market with responding to dramatically changing high crude oil price in recent years.
\end{abstract}

\section{Key Words}

LNG CIF price, Crude oil price, Cointegration, Elasticity coefficient

\section{Introduction}

Since natural gas burns more cleanly with fewer emissions of sulfur, carbon, and nitrogen against coal or oil and it has almost no ash particles left after burning, the demand of natural gas, especially for electricity generation, has grown so much and is expected to grow even more in the future. However, much of the world's known natural gas reserves are inconveniently located in remote areas such as the Middle East, South East Asia and Russia ${ }^{1)}$ from the main demand markets (Japan, EU and USA). Although there is at present a pipeline network connecting between Russia and EU countries across the Eurasia continent, pipeline transport is generally not an economically feasible option for transporting natural gas across oceans. As an alternative approach, Liquefied Natural Gas (LNG) is a proven commercial technology for transporting natural gas across oceans. Consequently, with the fast growing natural gas demand of the main markets without enough domestic production, the studies about LNG trade mechanism and the LNG trade price have become important subject for

Graduate School of Energy Science, Kyoto University

Gokasho, Uji, Kyoto 611-0011, Japan energy issues in recent years.

The natural gas is considered as a substitute for the oil in many fields and consequently the LNG transaction price and crude oil transaction price are considered to be interrelated with each other. In previous studies, the cointegration relationships between the CIF prices of Liquefied natural gas (LNG) and the crude oil prices were investigated ${ }^{2)-7)}$, and they were concluded that the LNG CIF prices are cointegrated with respective crude oil prices in Japan, EU and USA. This means that the LNG CIF price will be affected by the crude oil price directly or indirectly in Japan, EU and USA.

However, LNG has no international unified market like the crude oil, and the LNG CIF prices in Japan, EU and USA are different with each other due to their respective market mechanisms. Since past work has not made an explicit inter-comparison between the main LNG markets of Japan, EU and USA, our study was motivated to clarify the LNG price mechanisms of these three regional markets then to represent the relationships between the respective prices of LNG and crude oil quantitatively by elasticity coefficient. The elasticity coefficient means the percentage reaction of 
a dependent variable to a percentage change in an independent variable, and the elasticity coefficient of the LNG price to the crude oil price is an indicator to show the relationship between the growth rates of them. In this study, the respective long-run elasticity coefficients between the LNG CIF prices with crude oil prices of Japan, EU and USA were obtained by using cointegration and the Error Correction Model (ECM) techniques for the respective monthly price data of LNG and crude oil of these three regional markets in the time period from the 1998 to the 2006. And, the obtained long-run elasticity coefficient result can be used to explain the different changes of the LNG prices of these three regional markets due to the fast growing of crude oil price in recent years.

This paper is organized as that, the following section introduces the price mechanisms of LNG markets in Japan, EU and USA. The price time series modeling processes by cointegration theory are described in section 3. Section 4 presents the processes of calculation for the long-run elasticity coefficient between LNG prices and crude oil prices in Japan, EU and USA. And, the conclusion is given in section 5.

\section{LNG Market Mechanisms}

\subsection{LNG Pricing Mechanisms in Japan}

In Japan, the annual NG consumption is $81.1 \mathrm{Bcm}$ in 2005 , and more than $96 \%$ of the supply comes from LNG import from overseas through the 25 LNG terminals due to no substantial domestic reserves ${ }^{9}$. In order to guarantee the stabilization of the LNG supply (energy security policy), the LNG contracts of Japan are almost in the form of longterm contracts (about 20 to 25 years) with Take-or-Pay clauses, although the spot transactions are increasing for meeting the flexible demands in recent years, they are still relatively insignificant as compared with long-term contracts $^{10}$. From the year of 1985 , the detailed pricing mechanism of LNG contracts in Japan are mainly in the form of JCC (Japan Crude Cocktail) linkage which indexes the LNG CIF price to average imported crude oil price with S-curve except Indonesia. The CIF price of LNG imported from Indonesia indexes with the Indonesian Crude Prices $(\mathrm{ICP})^{11}$. For the JCC linked LNG trading, although the different contracts may employ different coefficients in the pricing formulas which are rarely disclosed, yet they are all linked to JCC basically in the same shape as shown in Fig. 1. The character of this pricing mechanism is that it can guarantee the interests of the sellers if the price of the benchmark crude oil drops below a certain threshold, and protect the interests of the buyers if it rises above a given ceiling ${ }^{12}$. However, the ICP pricing mechanism has no any

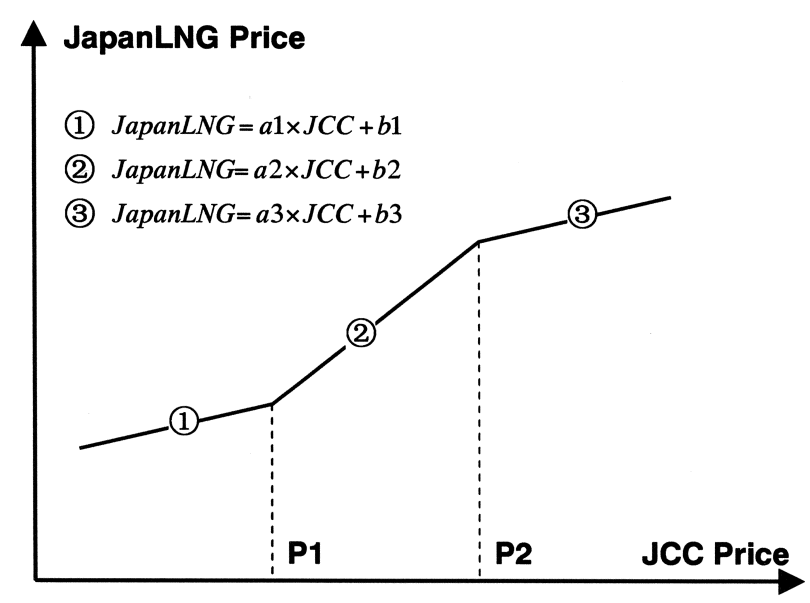

Fig. 1 Concept figure of the "S-curve" formula of JapanLNG

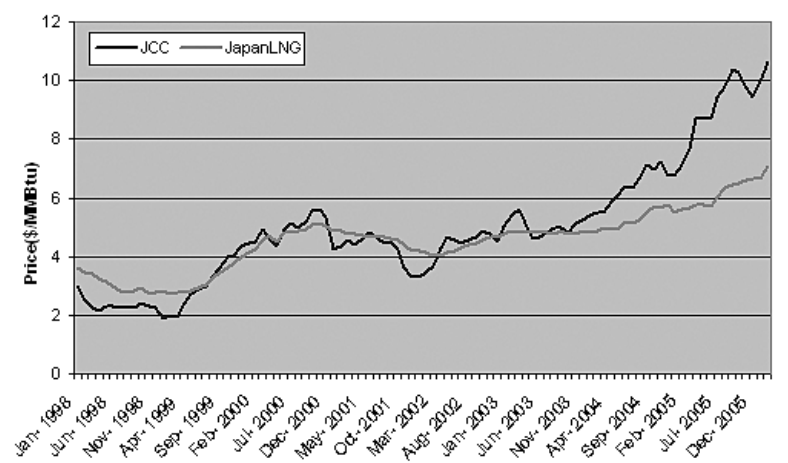

Fig. 2 Monthly price data of JCC and JapanLNG (Mar.1998-Feb. 2006)

protection function like S-curve as shown in Eq.(1). The total LNG CIF price of Japan is a mixture of JCC with ICP mechanisms and JCC mechanism is the dominant, and the monthly price data of JCC and JapanLNG from 1998 to 2006 is displayed in Fig. 2.

$$
\text { JapanLNG }=a \times I C P+b
$$

\subsection{LNG Pricing Mechanisms in EU}

The natural gas supply of EU mainly comes from the domestic production, pipeline imported from Russia, Norway and North Africa. The LNG import through ten terminals from North Africa and Middle East only occupies about $10 \%$ of the whole consumption- $471.2 \mathrm{Bcm}$ in $2005^{9)}$. However, more LNG will be imported in the future in order to satisfy the increasing natural gas needs in EU, and about 10 LNG terminals are under construction at present ${ }^{10}$. Presently, there are two different LNG pricing mechanisms widely used in EU depending on the supplies. In general formula for Nigeria and Trinidad\&Tobago can be specified liked the Eq.(2) (GO, LSFO, HSFO represent the gas oil, low sulphur and high sulphur oil, the footnote-0 represent the initial value), and the formula from Algeria, Middle East and Egypt are linked to Brent directly as shown in Eq. (3) ${ }^{10)}$. Although, it is expected that the oil price linkage will be- 


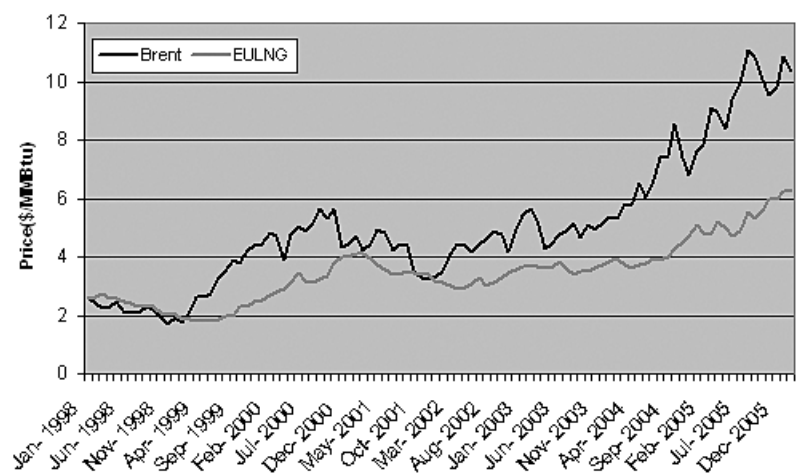

Fig. 3 Monthly price data of Brent and EULNG (Mar.1998-Feb. 2006)

come less significant in future as gas-to-gas competition increases, yet the oil will still be a major determinant of the gas price in the near and medium term in EU since the majority of existing long-term contracts are linked to the oil price ${ }^{7}$. The LNG prices in EU are highly responsive to the price changes in crude oil, and exhibits a high volatility as shown in Fig. 3 comparing with JCC link mechanism of Japan.

$$
\begin{aligned}
& E U L N G=P 0[(a \times G O / G O 0)+b(L S F O / L S F O 0) \\
& +c(H S F O / H S F O 0)] \\
& E U L N G=a \times \text { Brent }+b
\end{aligned}
$$

\subsection{LNG Pricing Mechanisms in USA}

In USA, the total NG consumption is $633.5 \mathrm{Bcm}, 81 \%$ of the supply comes from the domestic production, $16 \%$ from pipeline import from Canada, and 3\% from LNG import in 20059). However, the pipeline input from Canada has been decreasing; the export from USA to Canada and Mexico by pipeline has been increasing year by year on the other hand. Consequently, the LNG will play more and more important roles to meet the rapid increasing NG demand of USA ${ }^{10}$. But unlike natural gas prices in Europe and Japan, the LNG CIF price in US is determined by the natural gas competitive market usually taking the spot price in Henry Hub as the benchmark. In fact, some large customers (primarily

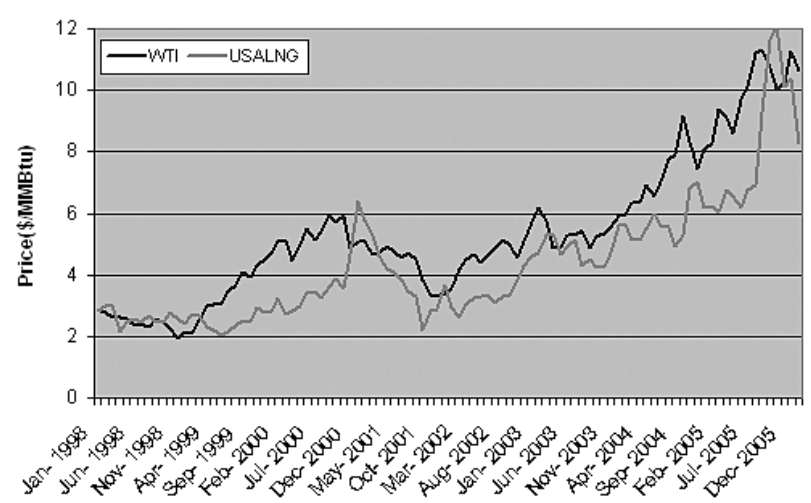

Fig. 4 Monthly price data of WTI and USALNG (Mar.1998-Feb. 2006) industrial consumers and electricity generators) can switch between natural gas and oil depending on their prices. Because of this correlation between the both fuel markets, the shift in demand to natural gas drives prices upward when oil prices rise as shown in Fig. 4.

\section{Modeling Price Time Series Using Cointegration Method}

The existing relationships between the LNG CIF prices and crude oil price are described in previous section in respective markets. The correlation between them will be estimated quantitatively in this section. The proper way is as follows. First, the time-series properties in terms of stationary of all the variables and the cointegration relations among them will be investigated. Then if the variables are found to be non-stationary but cointegrated, the long-run elasticity coefficient can be estimated by using cointegration and ECM methods. In this paper, the respective monthly LNG and crude oil price data from Mar. 1998 until Feb. 2006 of Japan, EU and USA reported in the Energy Prices and Taxes (IEA) are employed ${ }^{8}$. As shown in the Nomenclature, the LNG prices in Japan, EU and USA are the CIF (Cost, Insurance and Freight) prices are denoted as JapanLNG, EULNG and USALNG respectively, JCC, Brent and WTI are used to denote the respective crude oil prices of them. JCC means the average of the crude oil CIF prices imported into Japan from overseas, and the Brent and WTI are spot prices which are used as the price benchmarks in EU and USA crude oil markets respectively. In order to ensure compatibility between these different price data, all of the prices are counted as $\$ /$ MBtu where the conversion factor between the $\$ /$ barrel to $\$ /$ MBtu is 5.8 according to the BP statistical yearbook ${ }^{9}$.

Generally speaking, the LNG CIF price follows the developments of the crude oil price with an occasional lags, and this number is different according to the detailed contracts $^{1112)}$. Through enough tests and for the optimum result, we employ the three month leaded crude oil prices in EU (Dec.1997-Nov.2005) and two month leaded crude oil prices in Japan (Jan.1998-Dec.2005), and one month leaded crude oil price for USA (Feb.1998-Jan.2006) ${ }^{13)} \mathrm{com}^{-}$ paring with the LNG CIF data (Mar.1998-Feb.2006) with 96 observations. Furthermore, different from the uniform price mechanisms of EU and USA in the whole period from Mar.1998 to Feb.2006, due to the "S-Curve" price mechanism of Japan LNG market, and from the year of 2003, the crude oil price began coming into a high era, the monthly price data of LNG and crude oil of Japan is divided as two segments, from Mar. 1998 to Dec. 2002, and from Jan. 2003 to Feb. 2006 which are called as Japan(M) and Japan(H) 
respectively. And, Japan (M) and Japan (H) include 58 and 48 observations respectively. And, all the price series have been transformed to natural logarithms to remove the scale effects in the variables according to the past cointegration analysis work $^{1) \sim 7 \text { ) }}$.

\subsection{Stationary Analysis of the Price Time Series}

Typically, price time series are non-stationary, therefore, the analysis using classical regression approach may be faulty and subjects to spurious results. In this situation, the cointegration methodology emerged as a powerful analysis framework for dealing with them. Before the cointegration analysis, the time series properties of the data should be investigated. Therefore, the ADF (Augmented Dickey-Fuller) test and PP (Phillips-Perron) test were conducted for the price series with the maximum lags 11 and the optimum lag length was automatically chosen by the software Eviews5.014). The test results are reported in Table 1. Both of the two test methods show that at the 5 percent confidence level, the hypothesis of no unit root for each price series under consideration is rejected in levels but accepted in first difference, indicating that all of them are not stationary but the first order differences are station- ary, they are integrated of order one, written as I(1). In this case, the cointegration analysis can be carried out for them.

\subsection{Cointegration Analysis of the Price Time Series}

Engle and Granger pointed out that a linear combination of two or more non-stationary series may be stationary ${ }^{15)}$. If such a stationary linear combination exists, the non-stationary time series are said to be cointegrated. The stationary linear combination is called the cointegrating equation and may be interpreted as a long-run equilibrium relationship among the variables. Engle and Granger propose a regression of them as shown in Eq.(4), and determine cointegrating relationship between two $I(1)$ time series $X_{t}$ and $Y_{t}$, through checking whether the regression residual $\mu_{t}$ is stationary or not, which is called Engle-Granger twostep method.

$$
Y_{t}=\alpha+\beta X_{t}+\mu_{t}
$$

However, the Engle-Granger two-step method is said to be sensitive to the choice of dependent variables; therefore the test may not be consistent, which is seldom used at present in fact $^{16)}$. Therefore, the improved alternative method proposed by Johansen which is presently widely used is employed in this study to test the cointegration

Table 1 ADF and PP stationary test results for the price data of LNG and crude oil in Japan, EU and USA

\begin{tabular}{c|c|c|l|c|c|c}
\hline \multirow{2}{*}{ Variable } & \multicolumn{3}{|c|}{ Log level } & \multicolumn{3}{c}{ First order difference log level } \\
\cline { 2 - 7 } & ADF & PP & Result & ADF & PP & Result \\
\hline JapanLNG(H) & -0.39 & -0.14 & Non-stationary & -4.89 & -4.82 & Stationary \\
\hline JapanLNG(M) & -1.40 & -0.91 & Non-stationary & -5.79 & -5.04 & Stationary \\
\hline EULNG & 0.46 & -0.03 & Non-stationary & -8.48 & -8.61 & Stationary \\
\hline USALNG & -1.05 & -0.96 & Non-stationary & -10.16 & -10.33 & Stationary \\
\hline JCC(H) & 0.27 & 0.66 & Non-stationary & -4.93 & -4.77 & Stationary \\
\hline JCC(M) & -1.45 & -0.99 & Non-stationary & -5.34 & -5.30 & Stationary \\
\hline Brent & -0.60 & -0.60 & Non-stationary & -9.90 & -9.90 & Stationary \\
\hline WTI & -0.38 & -0.39 & Non-stationary & -8.96 & -8.93 & Stationary \\
\hline
\end{tabular}

ADF: Augmented Dickey-Fuller (ADF) Test $\quad$ PP: Phillips-Perron(PP) test. Test critical values at 1\% and $5 \%$ significance levels for EU and USA are $-3.5,-2.89$, and $-3.62,-2.94$ for the Japan. $(\mathrm{H})$, -3.55 and -2.91 for Japan(M); Tests for the price log level and first difference of log level are performed with intercept but no linear tread for the ADF and PP tests.

Table 2 Cointegeration test results for price data of LNG and Oil in Japan, EU and USA

\begin{tabular}{l|c|c|c|c|c}
\hline & $\mathrm{H} 0:$ rank $=\mathrm{p}$ & Trace Test & $5 \%$ & Max Test & $5 \%$ \\
\hline \multirow{2}{*}{ Ln(JapanLNG(H)), Ln( JCC(H)) } & $\mathrm{P}=0$ & 24.90 & 15.49 & 24.26 & 14.26 \\
\cline { 2 - 6 } & $\mathrm{P} \leqq 1$ & 0.65 & 3.84 & 0.65 & 3.84 \\
\hline \multirow{2}{*}{ nn(JapanLNG(M)), Ln( JCC(M)) } & $\mathrm{P}=0$ & 35.32 & 15.49 & 33.76 & 14.26 \\
\cline { 2 - 6 } & $\mathrm{P} \leqq 1$ & 1.56 & 3.84 & 1.56 & 3.84 \\
\hline \multirow{2}{*}{ Ln(EULNG), Ln(BRENT) } & $\mathrm{P}=0$ & 35.20 & 15.49 & 35.17 & 14.26 \\
\cline { 2 - 6 } & $\mathrm{P} \leqq 1$ & 0.03 & 3.84 & 0.03 & 3.84 \\
\hline \multirow{2}{*}{ Ln(USALNG), Ln(WTI) } & $\mathrm{P}=0$ & 16.14 & 15.49 & 16.00 & 14.26 \\
\cline { 2 - 6 } & $\mathrm{P} \leqq 1$ & 0.13 & 3.84 & 0.13 & 3.84 \\
\hline
\end{tabular}

All the tests were conducted at the third assumption of JJ test: Data has linear trends but the cointegrating equations have only intercepts 
relationship between respective LNG prices and corresponding crude oil prices in Japan, EU and USA. The cointegration test results by using the Johansen method are reported in Table 2, which suggest that the respective LNG prices and corresponding crude oil prices are cointegrated for Japan, EU and USA; i.e. there are long-run equilibrium relationships existing between them.

\section{ECM and Elasticity Coefficient Analysis}

The presence of the cointegration relationship between respective LNG prices and corresponding crude oil prices has been testified in the previous section for Japan, EU and USA. The construction of ECM and elasticity coefficient analysis is given in this part.

The ECM and The long-run cointegration relationship between two $I(1)$ series- $Y$ and $X$ could be represented by the error correction model (ECM) in the following form as shown in Eqs.(5) and (6), where $\lambda$ is a constant, both $m$ and $n$ are the number of the lags large enough to make the disturbance term $\varepsilon \mathrm{t}$ white noise. $Z_{t-1}$ is Error Correction Term (ECT), which is derived from the long run cointegration relationship as shown in Eq.(4); therefore the coefficient $\omega_{1}$ is thus the long-run elasticity of the $Y$ with respect to the $X$. The detailed regression results of the Japan (H), Japan(M), EU and USA are reported as the following equations. Various test results show that the values of the Akaike information criterion (AIC) are small enough when two level lags were chosen, and the adjusted R square and F-Statistic values are big enough to prove the linear relationships.

In our study, the price data has been transformed as the natural logarithms format, therefore the long-run elasticity of LNG price and crude oil price $\left(E_{y x}\right)$ can be obtained according to Eq. (7). The results are listed in Table 3. The values of $\omega_{1}$ in the ECM reveal the long-term elasticity between LNG price and crude oil price of Japan(H), Japan (M), EU and USA which are 0.49, 0.70, 0.76 and 0.96 respectively.

$$
\begin{aligned}
& \Delta Y_{t}=\lambda+\sum_{i=1}^{m} \alpha_{i} \Delta Y_{t-i}+\sum_{i=1}^{n} \beta_{j} \Delta X_{t-j}+\Phi Z_{t-1}+\varepsilon t \\
& Z_{t-1}=Y_{t-1}-\omega_{0}+\omega_{1} X_{t-1} \\
& \omega_{1}=\frac{\Delta \ln y_{t}}{\Delta \ln x_{t}}=\frac{\ln y_{t}-\ln y_{t-1}}{\ln X_{t}-\ln X_{t-1}}=\frac{\ln \left(y_{t} / y_{t-1}\right)}{\ln \left(x_{t} / x_{t}-1\right)} \\
& \approx \frac{\left(y_{t}-y_{t-1}\right) / y_{t-1}}{\left(X_{t}-X_{t-1}\right) / X_{t-1}}=E_{y x}
\end{aligned}
$$

$\Delta \operatorname{Ln}\left(\operatorname{JapanLNG}(H)_{t}\right)=0.255 \Delta \operatorname{Ln}\left(\operatorname{JapanLNG}(H)_{t-1}\right)+$ $0.040 \Delta \operatorname{Ln}\left(\operatorname{JapanLNG}(H)_{t-2}\right)-0.136 \Delta \operatorname{Ln}\left(J C C(H)_{t-1}\right)-$ $0.164 \Delta \operatorname{Ln}\left(J C C(H)_{t-2}\right)-0.716 Z_{t-1}+0.015$

Sample Period: Jan.2003 to Feb.2006, R2:0.36, Adjusted R2:0.30, F-Statistic $=2.50, \mathrm{AIC}=-8.06$

$Z_{t-1}=\operatorname{Ln}\left(\operatorname{JapanLNG}(H)_{t-1}\right)-0.082-0.487 \operatorname{Ln}\left(J C C(H)_{t-1}\right)$
Table 3 Long-run elasticity coefficient of the prices of LNG and crude oil in Japan, EU and USA ( $\omega+$ in Eq.(6))

\begin{tabular}{c|c}
\hline Item & Long-run elasticity coefficient \\
\hline Japan(H) & 0.49 \\
\hline Japan(M) & 0.70 \\
\hline EU & 0.76 \\
\hline USA & 0.96 \\
\hline
\end{tabular}

$\Delta \operatorname{Ln}\left(\operatorname{JapanLNG}(M)_{t}\right)=0.149 \Delta \operatorname{Ln}\left(\operatorname{JapanLNG}(M)_{t-1}\right)+$ $0.514 \Delta \operatorname{Ln}\left(\operatorname{JapanLNG}(M)_{t-2}\right)+0.082 \Delta \operatorname{Ln}\left(J C C(H)_{t-1}\right)+$ $0.120 \Delta \operatorname{Ln}\left(J C C(H)_{t-2}\right)-0.014 Z_{t-1}+0.003$

Sample Period: Mar.1998 to Dec.2002, R2:0.36, Adjusted $\mathrm{R} 2: 0.18, \mathrm{~F}-$ Statistic $=5.6, \mathrm{AIC}=-7.45$

$Z_{t-1}=\operatorname{Ln}\left(\operatorname{Japan} L N G_{t-1}\right)-0.762-0.70 \operatorname{Ln}\left(J_{C C_{t-1}}\right)$

$\Delta \operatorname{Ln}\left(E U L N G_{t}\right)=0.016 \Delta \operatorname{Ln}\left(E U L N G_{t-1}\right)+0.105 \Delta L n$ $\left(E_{L U N G t-2}\right)+0.132 \Delta \operatorname{Ln}\left(\right.$ Brent $\left._{t-1}\right)+0.077 \Delta \operatorname{Ln}\left(\right.$ Brent $\left._{t-2}\right)$ $+0.04 Z_{t-1}+0.014$

Sample Period: Mar.1998 to Feb.2006, R2: 0.40, Adjusted R2:0.36, F-Statistic $=11.48$, AIC $=-5.38$

$Z_{t-1}=\operatorname{Ln}\left(E U L N G_{t-1}\right)-0.073-0.756 \operatorname{Ln}\left(\right.$ Brent $\left._{t-1}\right)$

$$
\begin{aligned}
& \Delta \operatorname{Ln}\left(U_{S A L N G}\right)=0.096 \Delta \operatorname{Ln}\left(U_{S A L N G}-1\right)-0.009 \Delta \operatorname{Ln} \\
& \left(U S A L N G_{t-2}\right)-0.207 \Delta \operatorname{Ln}\left(W_{t-1}\right)+0.083 \Delta \operatorname{Ln}\left(W_{t-2}\right) \\
& +0.276 Z_{t-1}+0.016
\end{aligned}
$$

Sample Period: Mar.1998 to Feb.2006, R2: 0.18, Adjusted $\mathrm{R} 2: 0.17, \mathrm{~F}$-Statistic $=3.52, \mathrm{AIC}=-3.47$

$Z_{t-1}=\operatorname{Ln}\left(U S A L N G_{t-1}\right)+0.146-0.964 \operatorname{Ln}\left(W_{T I-1}\right)$

The elasticity coefficient is a measure of responsiveness degree of one variable to the change of another. The elasticity coefficient of the LNG price and the crude oil price is an indicator to show the relationship between the growth rate of crude oil price and the growth rate of the LNG price. According to the results in Table 3, the protection of S-curve in the LNG price of Japan can be found in the high oil price period $(0.70>0.49)$. It is a common sense that the JCC, Brent and WTI only have a small difference in value and have the same development trend due to the uniform world crude oil market, so the respective elasticity coefficients between LNG prices and oil prices in Japan, EU and USA can be used to explain the different reactions of LNG prices with response to the crude oil price. The large elasticity coefficient means the change of oil price will exercise a large influence on the corresponding LNG price while the small one means a small influence on the other hand. So in the era of high oil price the LNG price of USA will be affected by the oil price most significantly, then is the EU, the last is Japan (0.96>0.76>0.49). As shown in Fig.5, historically, Japan LNG price remained higher as compared to USA and 


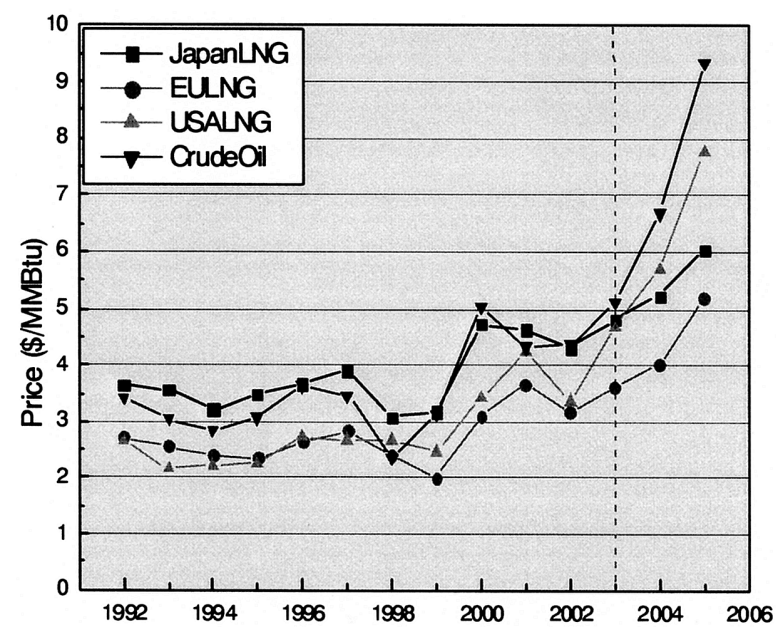

Fig. 5 Annual price data of LNG comparison for Japan, EU and USA

EU on an average, however, the gap between the LNG prices of Japan and EU became smaller and the USA LNG price exceed that of Japan in the era of high oil price of recent years. Furthermore, many LNG contracts of Japan will be finished before 2010, the ceiling price of the S curve for new contracts may increase than previous ones ${ }^{10)}$ to present a larger coefficient between the prices of LNG and crude oil. As a matter of fact, the LNG transaction mechanisms of Japan, EU and USA are also affected by the transaction mechanisms of natural gas by pipeline due to the competition between the both transactions. The influence of this effect on the elasticity coefficient will be further studied in future.

According to analysis results of this study about the relationships between the LNG prices and crude oil prices in the world three largest LNG markets- Japan, EU and USA, some other problems are also implicated. In fact, in the past several years, the world economy grew fast with a rate of about 5\% annually on average, and this strong trend will continue at least in the near future especially when the market prosperity and the domestic demand enlarge in China, India, EU and Japan are considered ${ }^{17}$. Consequently, the energy demands also have been increasing quickly especially for the oil. However, the production capacity of the crude oil has appeared severe lack in the world range, which makes the crude oil price climb up quickly. With a response to oil price, the natural gas price also has been moving up quickly as analyzed in this study. In other word, the supplies of oil and the natural gas will become more and more instable, especially for the countries highly depending on the energy import like Japan. Furthermore, the abundant utilization of the coal is rejected due to the $\mathrm{CO}_{2}$ emission problem. Thus, for Japan maybe also for other countries, developing the nuclear and the renewable energy greatly should be proposed as the essential policies ${ }^{1819)}$ from economy and energy security viewpoints in the high energy price era.

\section{Conclusion}

The LNG CIF prices are linked to the crude oil prices directly or indirectly in Japan, EU and USA reflecting the competition nature between them. However, unlike the price of crude oil, there is no unified international market for LNG. Japan, EU and USA import their LNG by respective contract form according to the respective different market mechanisms. The "S curve" linkage contract form makes the LNG import price higher than that of the crude oil and that of EU and USA in most time in history before 2003 for Japan. However, the high crude oil price of recent years makes this situation to be inverted. The LNG import price of USA exceeded that of Japan and the gap between LNG import price of EU and Japan also has been decreasing.

The economic analysis results in this study by using cointegration and ECM techniques confirm that there are the long-run associations between LNG CIF prices with the respective crude oil prices in Japan, EU and USA, but the long-run elasticity coefficients are different which prove the different LNG price mechanisms. The obtained longrun elasticity coefficients can be used to explain the different LNG CIF price movements of each market in recent years with responding to the extremely high crude oil price.

Lastly, the energy policy for development of nuclear and renewable energy is proven to be preferred especially for the countries like Japan in the future from economy and energy security viewpoints in the high energy price era.

\section{References}

1) Energy Information Administration (EIA), The global liquefied natural gas market: status and outlook, (2003)

2) Siliverstoves, B., Guillaume, L., Neumann, A., Hirschhausen, C., Energy Economics, 27, 603(2005)

3) Neumann, A., Siliverstoves, B., Hirschhausen, C., Convergence of European Spot Market Prices for Natural GasA Real-Time Analysis of Market Integration using the Kalman Filter, 7th IAEE European Energy Conference, Bergen, Norway, (2005)

4) Asche, F., Osmundsen, P., Tveteras, R., Energy Economics, 24, 249(2002)

5) King, M., Cuc, M., The Energy Journal, 17(2), 47(1996)

6) Jose, A. V., Frederick, L. J., The relationship between the crude oil and natural gas prices, Office of oil and gas, (Energy Information Administration (EIA)), (2006)

7) Organization of the Petroleum Exporting Countries 
(OPEC), Forecasting natural gas prices using cointegration technique, (2006)

8) International Energy Agency (IEA). IEA statistics. Energy prices and taxes, 1998-2006, IEA, Paris, (1998-2006)

9) BP, BP statistical review of world energy 2006, (2006)

10) International Energy Agency (IEA), Natural gas market review 2006, IEA, Paris, (2006)

11) Fujime, K., LNG market and price formation in East Asia, IEEJ (2002)

12) Tsuzaki, K., Kawamoto, K., Market valuation of LNG price formulas, Proceedings of the 23rd conference on energy, economy, and environment, Tokyo, (2007 ) (In Japanese)

13) Energy Information Administration (EIA), The shortTerm energy outlook energy prices model regression results, http://www.eia.doe.gov/emeu/steo/pub/document/regpr.html, (2000)

14) Quantitative Micro Software, Eviews 5 Users Guide, http://www.eviews.com, p.519 (2005)

15) Engle, R. E., Granger, C. W. J. , Econometrica, 55, 251(1987)

16) Zuo. G. L, Chau. K. W., Energy Policy, (34), pp.3644-3655 (2006)

17) International Monetary Fund (IMF), World Economic Outlook-Spillover and cycle in the global economy, http:/ /www.imf.org , (2007)
18) Ministry of Economy, Trade and Industry (METI) of Japan, New energy strategy of the country, http:// www.meti.go.jp, (2006) (In Japanese)

19) Ministry of Economy, Trade and Industry (METI) of Japan, The plan of nation built on the nuclear, http:// www.meti.go.jp, (2006) (In Japanese)

$\begin{array}{ll}\text { NG } & \text { Natural Gas } \\ \text { LNG } & \text { Liquefied Natural Gas } \\ \text { JapanLNG } & \text { Japan LNG price(CIF) } \\ \text { JCC } & \text { Japan Crude Cocktail } \\ \text { EULNG } & \text { EU LNG price (CIF) } \\ \text { Brent } & \text { Brent crude oil price } \\ \text { USALNG } & \text { USA LNG Price(CIF) } \\ \text { WTI } & \text { West Texas Intermediate crude oil price } \\ \text { MBtu } & \text { Million British Thermal Unit } \\ \text { Bcm } & \text { Billion Cubic Meters } \\ \text { CIF } & \text { Cost, Insurance and Freight } \\ \text { FOB } & \text { Free On Board } \\ \text { ICP } & \text { Indonesian Crude Prices } \\ \text { ECM } & \text { Error Correction Model } \\ \text { Japan(H) } & \text { Monthly price data (Jan.2003 to Feb.2006) } \\ \text { Japan(M) } & \text { Monthly price data (Mar.1998 to Dec.2002) }\end{array}$

